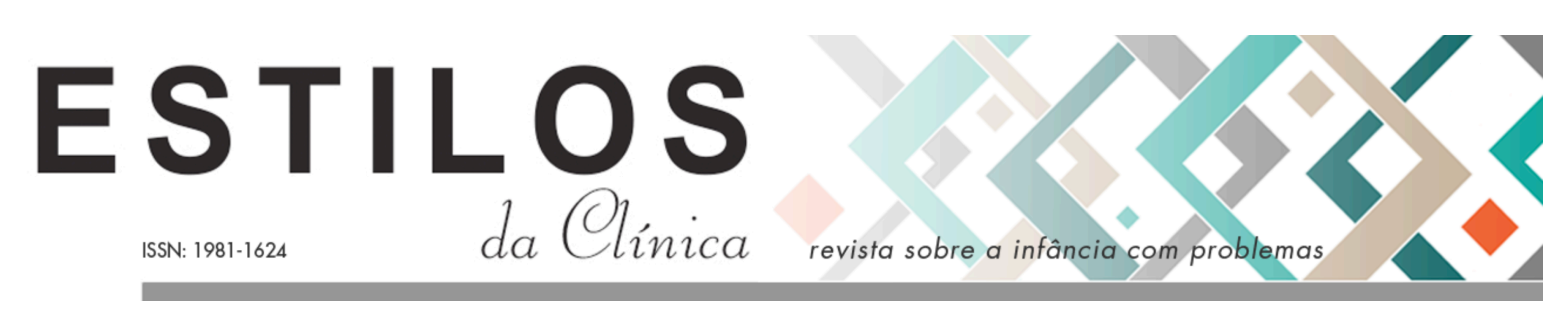

DOI: https://doi.org/10.11606/issn.1981-1624.v26i3 p435-444.

Dossiê

\title{
Psicanálise com crianças online? Reflexões sobre um atendimento durante a pandemia
}

\author{
Tiago Sanches Nogueira
}

Resumo. O presente artigo examina as vicissitudes de um atendimento clínico realizado com uma criança durante a pandemia. Trata-se de uma análise conduzida de forma online nos primeiros meses de confinamento, que exigiu do psicanalista algumas invenções táticas que pudessem viabilizar o tratamento. O estabelecimento de um ensino sobre como desenhar olhos, bem como o trabalho com fotografias em movimento (stop motion), surgiram como alternativas para o menino dominar o olhar obsceno do Outro. Ao final, a discussão sobre o modo como se dá o trabalho online nos levou à constatação de que, nele, encontramos a ocorrência de uma espécie de sutura daquilo que em teoria cinematográfica é chamado de campo e contracampo.

Palavras-chave: psicanálise com crianças; psicanálise online; olhar; pandemia.

\section{¿Psicoanálisis con niños en línea? Reflexiones sobre la atención durante la pandemia}

Resumen. Este artículo examina las vicisitudes de la atención clínica brindada a un niño durante la pandemia. Se trata de un análisis realizado online en los primeros meses de encierro que requirió algunos inventos psicoanalistas que pudieran hacer factible el tratamiento. El establecimiento de la enseñanza sobre cómo dibujar ojos, así como el trabajo con fotografías en movimiento (stop motion), surgieron como alternativas para que el niño dominara la mirada obscena del Otro. Al final, la discusión sobre la forma en que se desarrolla el trabajo online nos llevó a observar que en ella encontramos la ocurrencia de una especie de sutura de lo que en teoría cinematográfica se llama campo y contracampo.

Palabras clave: psicoanálisis con niños; psicoanálisis en línea; mirada; pandemia.

\section{Psychoanalysis with children online? Reflections on care during the pandemic}

Abstract. This article examines the vicissitudes of clinical care provided to a child during the pandemic. It is an analysis conducted online in the first few months of confinement that required some psychoanalyst from the psychoanalyst to make the treatment feasible. The establishment of teaching on how to draw eyes, as well as working with moving photographs (stop motion), emerged as alternatives for the boy to master the obscene look

\footnotetext{
* Psicanalista. Doutor em Psicologia Clínica pela Universidade de São Paulo (USP). Membro do Laboratório de Psicanálise, Sociedade e Política (PSOPOL-USP). São Paulo, SP, Brasil. E-mail: tiagosanchesnogueira@gmail.com
} 
of the Other. At the end, the discussion on how to give online work led us to the realization that it found the occurrence of a kind of suture what in film theory is called shot and reverse shot.

Keywords: psychoanalysis with children; psychoanalysis online; gaze; pandemic.

\section{Psychanalyse avec les enfants en ligne? Réflexions sur les soins pendant la pandémie}

Résumé. Cet article examine les vicissitudes des soins cliniques prodigués à un enfant pendant la pandémie. C'est une analyse menée en ligne dans les premiers mois de l'accouchement qui a nécessité des inventions psychanalystes qui pourraient rendre le traitement réalisable. La mise en place d'un enseignement sur la façon de dessiner les yeux, ainsi que le travail avec des photographies en mouvement (stop motion), ont émergé comme des alternatives pour que le garçon maîtrise le regard obscène de l'Autre. Au final, la discussion sur la manière dont s'effectue le travail en ligne nous a conduit au constat qu'on y trouve une sorte de suture de ce qu'on appelle en théorie cinématographique champ et contre-champ.

Mots-clés: psychanalyse avec les enfants; psychanalyse en ligne; regard; pandémie.

atendimento psicanalítico com crianças ficou impossibilitado no início da pandemia. A imposição do isolamento social devido à COVID-19 interrompeu os atendimentos presenciais, e logo os psicanalistas se viram diante de um impasse: como viabilizar e sustentar um espaço de trabalho que pudesse ser realizado à distância com as crianças? Seria possível pensar em atendimentos online?

Longe de ser uma unanimidade entre os analistas, tal prática precisa ser pensada com cuidado, sobretudo quando se trata de atendimento com crianças. Sim, pois sabemos que o uso excessivo de telas pode fazer muito mal aos pequenos, provocando-lhes verdadeiras intoxicações digitais (Jerusalinsky, 2017), tal como observamos muitas vezes na clínica. Além do mais, o universo online é um campo que exige cuidados, pois, nele, a fronteira entre o público e o privado não é bem demarcada e precisa ser constantemente assegurada pelos pais.

Segundo Belo (2020), o estabelecimento de um setting virtual exige dos psicanalistas um enfrentamento da idealização da prática, bem como uma depuração dos elementos técnicos e éticos que sustentam a escuta, o que permite a instalação de um espaço clínico não presencial. O autor lembra que mudanças no enquadre já foram feitas ao longo da história da psicanálise, tal como fez Ferenczi (1928/1992) com seu texto sobre a "elasticidade da técnica", e as modificações propostas por Winnicott $(1961 / 1986)$ para que casos mais graves pudessem ser acolhidos pela psicanálise.

A interpelação mais frequente feita pelos críticos do trabalho analítico online diz respeito à ausência dos corpos do analista e do analisante na sessão online. Nessa direção, temos trabalhos como de Miller (1999) e de Vivès (2018), que defendem a posição de que a copresença em carne e osso de analisante e analista se faz necessária, já que, segundo tais autores, os corpos não ressoam da mesma maneira numa sessão por telefone ou pela internet. Em contraste com essas posições, encontramos Bruce Fink (2017), que defende a ideia de que aquilo que é essencial em uma análise é a capacidade de escuta entre analista e paciente e, portanto, o encontro de corpos não é essencial a partir do momento em que alguém entra no discurso analítico. Dunker (2020) recentemente também defendeu a ideia de que o atendimento à distância é uma alternativa real, e que a presença física não deveria ser um impeditivo para o sujeito procurar uma análise nesse momento de exceção que estamos vivendo.

Fato é que momentos de crise como o atual nos impõem a árdua tarefa de inventar dispositivos de mediação que superem as dificuldades impostas por determinados 
acontecimentos, como é o caso do isolamento ao qual fomos submetidos durante a pandemia. Sabemos que os sofrimentos não poderão esperar até o final da pandemia para serem tratados, exigindo dos analistas certa flexibilização da técnica e, ao mesmo tempo, criatividade para a invenção de novos meios.

Partindo da ideia de que o atendimento psicanalítico possa ser realizado por outros meios, pensamos que computadores, tablets e celulares têm potencial para serem interessantes formas de mediação para nosso trabalho. Será a partir dessa aposta que apresentaremos a seguir o relato de um atendimento realizado com criança durante o período de isolamento imposto pela pandemia. Tal trabalho pôde nos ajudar a pensar formas de lidar com o distanciamento, bem como modalidades de intervenções online que pudessem viabilizar o tratamento nesse difícil momento.

\section{O professor de olhos}

Um garoto com dez anos de idade chega à análise no meio da pandemia. Já em quarentena, a mãe procura tratamento para o filho devido a questões específicas relacionadas ao seu comportamento: o menino apresenta dificuldades para obedecer a regras. Iniciamos o trabalho com a criança após várias entrevistas preliminares com os pais. Um dos primeiros movimentos do paciente através das telas foi o de ensinar maneiras de desenhar olhos humanos, passo a passo, dando ênfase ao brilho e aos efeitos de sombra e luz. Destacamos aqui o "empuxo a ensinar", que, desde o primeiro momento da análise, mostrou-se extremamente importante para ele. Voltaremos a isso logo mais, pois, no momento, iremos nos deter nessa curiosa prática de produzir um olhar no interior do desenho.

A situação da pandemia parece ter agravado um processo que já estava acontecendo com o menino: a forma singular como ele estava respondendo ao olhar do Outro. Sua demanda por reconhecimento já era gritante antes do confinamento, agravando-se após o fechamento das escolas e, consequentemente, o afastamento dos pares. Restringido apenas ao contato com o pai e com a mãe, o menino parece ter se congelado na posição daquele que apenas olha.

Rapidamente, não apenas o ensino se tornou remoto, mas também as práticas de prazer. $\mathrm{O}$ brincar se restringiu aos jogos eletrônicos, bem como o contato com os amigos ficou restrito às redes sociais. Neste sentido, um dos primeiros passos dados pelo analista foi o estabelecimento de certa mediação entre o universo da tela e o universo fora dela, advertindo a criança e os pais sobre aquilo do campo digital que afeta o corpo:

Não basta a presença real, é preciso que o Outro encarnado possibilite mediar uma metaforização do que afeta o corpo. Como se inscreve o ideal do eu que funciona como mira para que seja possível realizar as travessias da vida, sem cair de angústia a cada passagem? Para onde o Outro encarnado olha? Se alguém se sente solto, flutuando na tela do computador, é porque lhe é frágil a possibilidade de servir-se da referência simbólica para representar o âmago do seu afeto corporal, que lhe permita aceder a palavra que o toca no cerne de sua articulação pulsional. Desse modo, fica-se em presença excessiva do objeto, mas subjetivamente à deriva (Jerusalinsky, 2017, p. 50).

Constatamos, portanto, que a posição do garoto em ser aquele que apenas olha remetia a certa posição de objeto vivenciada no laço com os pais. Nessa posição, o paciente parecia estar impossibilitado de receber o testemunho do olhar do outro, que é responsável por decantar o reconhecimento de sua própria imagem (Lacan, 1960/1998, p. 685). Era evidente o sofrimento 
da criança expresso através de comportamentos agressivos e da tentativa de controle das ações dos pais. A imagem que ele parecia criar de si mesmo, a imagem de uma criança "não ideal", promovia certa diferenciação da imagem que os pais demandavam dele.

Ser o desobediente ou agressivo acabou se tornando uma espécie de defesa contra as demandas narcísicas dos pais. Se por um lado o comportamento sintomático do menino assinalava a verdade conflituosa do casal, por outro, fazia de tais comportamentos uma importante defesa contra a identificação com certo Ideal de Eu proposto pela mãe. O imperativo de desenhar olhos apresentado pelo paciente, nesse sentido, foi lido pelo analista como uma pista de que objeto da fantasia materna ao qual estava convocado tinha algo a ver com olhar, sobretudo naquilo que o prazer de ver se articula com o prazer de saber. Logo, constatamos a urgência inicial de instituição de um olhar que, além de apenas demandar, pudesse também autenticar seu apelo por reconhecimento.

\section{Questões sobre o atendimento online}

Lacan (1964/1985, p.104) nos lembra que o olhar está do lado de fora, e o que determina o sujeito no campo do visível é, justamente, o fato dele ser olhado como se fosse um quadro. Eis a dificuldade que encontramos inicialmente no atendimento online, já que o enquadramento das telas estabelece um lugar fixo e único para o sujeito situar seu olhar, diminuindo a distância de si a si mesmo e dificultando a construção da fantasia numa certa perspectiva.

Ser visto como um quadro não exclui o fato que, do outro lado, o paciente também está vendo o analista como um quadro. Há ainda um agravante nisso: nesse quadro, encontramos uma mancha que é a própria imagem do sujeito que, na maior parte dos dispositivos de videoconferência, não pode ser excluída do campo visual. O impacto desse encontro constante com o espelho é algo a ser considerado, e o manejo desse novo setting deve levar em conta tais propriedades visuais.

Lembremos que a tela do computador, do tablet ou do celular surge aqui como a tela de uma pintura, que se apresenta como suporte de uma complexa operação que acontece fora da tela. É o que Lacan (1965-66) chama de função da tela enquanto suporte da significação. O exemplo trazido por ele em relação a essa função é o das pinturas rupestres, nas quais encontramos a presença de linhas que nos indicam cadeias estruturais, cuja essência é propriamente significante e que revelam a função da tela enquanto suporte da significação.

Tanto as paredes da caverna, quanto a tela do pintor, ou ainda a própria tela dos gadgets eletrônicos de hoje em dia, são lugares de suporte de significação. Qual significação? A que brota daquilo que organiza nosso campo visual: a perspectiva. Fundadora da visão moderna, a perspectiva apresenta o mundo como um "a ver", ao mesmo tempo em que constitui o sujeito como aquele que olha (Lacan, 1964/1985).

Será nesse sentido que, no setting online, o analista não poderá se descuidar daquilo que Lacan chamou de "apetite do olho". Trata-se do valor de encanto que encontramos em tais telas, sejam elas pinturas ou telas eletrônicas. Sim, pois, insaciável, o olho parece buscar uma pacificação através de um esfomeado "dar a ver":

No que é que esse dar a ver pacifica alguma coisa? - senão nisto, que há um apetite do olho, que se trata de alimentar, constitui o valor de encanto da pintura. Esse valor é, para nós, a ser procurado num plano bem menos elevado do que se supõe, naquilo que é a verdadeira função 
do órgão do olho, o olho cheio de voracidade, que é o do mau-olhado (Lacan, 1964/1985, p. 112).

Diante dessas reflexões, nossa hipótese foi de que a reprodução de olhos servia para nosso paciente como aquilo que Lacan (1964/1985) chamava de imagem anteparo - um véu de representação que recobre o objeto olhar. Trata-se de uma espécie de cortina que vela e revela, camuflando o sujeito ao apresentar outra coisa para o olhar imediato que, ao mesmo tempo, indica onde está o desejo. Logo, a imagem anteparo é um dar a ver que pacifica, mas que não deixa de apontar algo do sujeito. Nesse caso, parecia existir algo referente a uma dificuldade de se proteger do olhar do Outro.

A imagem anteparo produzida por nosso paciente parecia apontar para um importante fato: de que "o homem para ser homem, para viver, deve ter sua zona de sombra [...] e que o inferno está manifestamente estruturado como o Panóptico ${ }^{1}$ de Jeremy Bentham (Wajcman, 2006, p. 98-99)". O menino estava reivindicando a criação de sua própria zona de sombra. Miller (2008) comenta que os dois princípios fundamentais da construção panóptica são a posição central da vigilância e sua invisibilidade. Destacamos este último que mostra que, em tais construções, o olho vê sem ser visto. Desse modo, poder discernir o olhar que me olha é também ser capaz de dominar sua vigilância. É olhando-o que aprendo suas intermitências, seus deslizes, suas regularidades. Só assim posso despistá-lo: "Se o Olho está escondido, ele me olha, ainda quando não me esteja vendo. Ao se esconder na sombra, o Olho intensifica todos os seus poderes" (Miller, 2008, p. 91).

É preciso cuidar desse olho que tudo vê, pois, sob este olhar, encontramo-nos desabrigados e sem proteção. Nessa direção, Wajcman (2006) faz um interessante comentário: o autor refere que a primeira forma arquitetônica nasceu para que o homem também se protegesse desse olhar, entendendo que o íntimo é um lugar de essência arquitetônica e escópica, já que nele o sujeito pode se sentir abrigado do olhar do Outro. Este seria, portanto, um espaço de exclusão interna, no qual podemos nos esconder: "este ponto da arquitetura não humaniza um espaço, instaura uma humanidade enquanto tal, dando ao homem a possibilidade da sombra, e com esta a do segredo" (Wajcman, 2006, p. 97).

Observa-se aqui que a função do analista como pequeno outro na posição de olhar receptivo dá vida ao segredo de nosso paciente. Mostrando que o paciente tira sua consistência não de um olhar que não vê, mas de um olhar que vê claramente, o analista tenta viabilizar, através de seu testemunho, a constatação de que a "Coisa humana" exilada da experiência não precisa se esconder para estar escondida.

\section{Maîtriser o apetite do olho}

Durante os atendimentos, o menino apresenta uma saída muito interessante, que convida o analista a participar daquilo que seria uma forma de controlar o olhar. Trata-se de estabelecer um ensino sobre a prática de desenhar olhos, na qual o menino propõe ao analista "aulas" em que ele se apresenta como um professor, um mestre da arte de representar olhos.

1 Panóptico é um termo utilizado para definir um conceito de edifício institucional desenhado por Jeremy Bentham (1787/2008),_no final do século XVIII. Essse edifício teria como função ser uma prisão, construído numa forma circular, a qual permitiria a vigilância de um maior número de prisioneiros através de menor policiamento e utilização de recursos administrativos. 
O fazer do menino nos remete ao termo francês maîtriser, que significa o domínio de algo, como o domínio de uma paixão ou emoção, por exemplo. Contudo, a palavra contém também em si a ideia de se tornar mestre, tal como quando o domador domina o cavalo. Apontamos aqui para a presença do discurso do mestre - esse tipo de discurso que aliena o agente ao outro, guardando em sua estrutura um pedido de dominação: "me ser, me seja". Sim, pois Lacan lembra que o "discurso do mestre ao se escrever como $m$ 'être ('me ser'), coloca o acento sobre o verbo ser" (Lacan, 1972-73/1985).

A proposta do paciente de se tornar "professor de desenho" é tomada pelo analista como uma oportunidade para que ele se desloque do lugar de dominado. Para isso, o menino-professor precisaria realizar a complexa operação de "sair do saber ao entrar nele" (Lacan, 1970/2003, p. 305), sustentando-se como sujeito produzido pelo saber que ele próprio tenta dominar. Essa complexa operação poderá ser viabilizada se o analista, através de seu manejo, conseguir fazer o saber passar a operar no lugar de agente do discurso. Estaríamos aqui investindo no quarto de giro que instituiria a passagem do discurso do mestre para o discurso do universitário.

Para Lacan, o saber serve de agente justamente por se revelar como ensino: "O ensino é o saber que é descaracterizado, em suma, pelo lugar de onde ele impera" (Lacan, 1970/2003, p. 306). Logo, o saber colocado no lugar de agente poderá produzir um sujeito-professor (não o contrário!). A organização de tal produção passou a ser o fio condutor da análise com o garoto, de modo que as intervenções do analista visassem o restabelecimento desse professor não mais como alguém dominado pelo olhar do Outro, mas como um sujeito que pudesse estar no registro da produção de um saber sobre esse olhar.

Maîtriser: dominar o olhar do Outro através de um ensino sobre este olhar. Não qualquer ensino, mas um ensino que pode, com ajuda do analista, fazer do saber um agente e não o produto do discurso. Na prática, estamos falando da instalação de um tipo de curiosidade (Wissbegierde) que poderia despertar no menino um desejo de ensinar algo sobre aquilo que ele sabe, e também aquilo que não sabe sobre o olho que o olha. Para isso, o analista decidiu refazer a montagem e o enquadramento da cena utilizando técnicas de filmagem nas quais o menino produzia outros tipos de olhares que poderiam ser manipulados, agora, por ele próprio.

Uma destas técnicas propostas pelo analista foi o stop motion - técnica de animação em que os objetos são fotografados quadro a quadro e, posteriormente, montados em vídeo, criando a impressão de movimento. Para que o movimento da técnica possa ser percebido, é preciso mudar de forma vagarosa a posição do objeto entre um quadro e outro, registrando as mudanças por meio de uma câmera fotográfica. A aposta no stop motion coloca a fotografia em cena, e, junto com ela, o tema da perda daquilo que um dia foi olhado, pois a foto é uma testemunha daquilo que não é mais (Barthes, 2004, p. 498).

No livro A Câmara Clara (1984), Roland Barthes descreve a fotografia como uma imagem que, fundamentalmente, lastima a imagem de um objeto ou indivíduo ausente, ao contrário de se deleitar com sua aparição no tempo presente. Logo, se a fotografia é a prova de que algo realmente aconteceu, ela também testemunha a queda de um olhar que pôde ser capturado ali naquele instante. Manusear um "ex-olhar" (um "olhar que não é mais"), recolocando-o a cada quadro, em stop motion, de modo que possamos recortá-lo, editá-lo, manuseá-lo, ajuda-nos a reescrever junto com o paciente a história do olho que tudo vê, ao mesmo tempo em que o permite se tornar um pouco mais senhor de seu próprio olhar.

As animações produzidas pelo paciente consistiam em movimentos simples, nos quais se formavam sorrisos através do manuseio de massinha de modelar. Em outro momento, ele fez um bonequinho se movimentar e, posteriormente, fez de seu próprio corpo uma animação em 
stop motion. A passagem do sorriso animado para um corpo modelado animado e, posteriormente, para o próprio corpo animado do garoto, marca a incidência gradual de uma certa presença da ausência do campo visual. De início, o resultado do trabalho eram apenas os sorrisos animados, pois o vídeo produzido não apresentava as imagens do analista e do paciente; numa etapa posterior, os corpos modelados de massinha eram vistos ainda sem a presença do sujeito que olha na cena; por último, o corpo em stop motion do garoto entra em cena e volta a ser visto pelo outro, agora inscrito em uma temporalidade Outra que reestrutura o campo visual, permitindo que o próprio paciente possa produzir um diferente olhar para si mesmo.

\section{O conceito de sutura ajudando a pensar a clínica online}

Se o trabalho do psicanalista que trabalha online se sustenta "entre telas", um de seus efeitos será o manejo de uma espécie de sutura daquilo que, em teoria cinematográfica, é chamado de campo e contracampo. Jacques Alain Miller (1966) utilizou o termo "sutura" para designar a relação em ausência do sujeito enunciante com sua conformação na cadeia do discurso.

Apesar de não ter sido anunciado explicitamente por Lacan, o conceito de sutura está presente em seu sistema teórico desde o momento em que inicia a discussão sobre a situação problemática do sujeito em relação ao discurso. As proposições do psicanalista francês sobre o tema colocam o sujeito num lugar vazio, fora da cadeia significante, justamente porque ele (o sujeito) é posicional em relação ao discurso. Sujeito e significante estão intimamente ligados, porém de um modo peculiar, já que o sujeito aparece no intervalo entre dois significantes (um significante representa o sujeito para outro significante). Nessa fenda que se abre entre um significante e outro, vemos o sujeito ser causado pela própria articulação significante, sem que ele necessariamente participe dela. A exclusão do sujeito para fora do discurso que interiormente ele produz é chamada de sutura por Jacques Alain Miller (1966).

Jean-Pierre Oudart (1969) adapta o conceito de sutura para o campo cinematográfico ao problematizar um elemento estilístico central que estrutura a narrativa cinematográfica: a alternância entre campo e contracampo. Campo e contracampo indicam a alternância de planos orientados no mesmo eixo dramático, porém em sentidos opostos. Trata-se da montagem invisível, a qual naturaliza, aos olhos do espectador, a ilusão de que os personagens ocupam o mesmo espaço cênico quando, na realidade, encontram-se separados. No universo online das videochamadas, podemos dizer que campo e contracampo se encontram suturados num mesmo plano, que é a tela onde as pessoas veem tanto o outro, quanto a si mesmas. Nessa situação, analisante e analista poderiam dizer um ao outro: lá onde você me olha, você não me vê. Assim como lá onde você acha que me vê, sou eu, tela, que estou te olhando.

Longe de querer equivaler a tela de atendimento com a tela de cinema, vemos aqui uma possibilidade de interrogar o trabalho online através de tal conceito de sutura, já que este nos ajuda a pensar o campo onde se encontra o espectador. Segundo Ramos (2000), Oudart traz para o coração da teoria do cinema a noção de espaço fora de campo, espaço onde se delineia o campo imaginário do espectador. Será este "campo ausente" que remeterá à sutura, conceito que tematiza em profundidade a dimensão "off" da imagem cinematográfica.

O discurso cinematográfico "sutura" o imaginário do espectador, impedindo que se manifeste como abertura de uma ausência:

O que nós aqui chamamos "sutura" é a representação daquilo que este termo designa como a relação do sujeito ao encadeamento de seu discurso: representação que se realiza sob o traço 
desta Soma Significante marcada por uma falta que é a falta de alguém, e de um Ausente que se abole para que alguém, que representa o elo seguinte (e antecipa o próximo segmento filmico), possa surgir (Oudart, 1969, p. 39).

Ramos (2000) lembra que esta Soma é marcada por uma falta que a dimensão fora de campo instaura na sucessão dos planos. Sendo assim, é ela que será "suturada" no transcorrer do discurso fílmico, instaurando um imaginário que aparece como sujeito (para o espectador) de uma visão que não é sua, mas que aparece como tal, pois foi costurada pela sobreposição, na consecução fílmica, da estrutura campo-contracampo.

Tais reflexões nos ajudam a pensar que, no atendimento online descrito neste texto, foi de fato observado que o analisante pôde ver o seu olhar desde um lugar de fora do plano. Nesse sentido, notou-se que no setting online campo e contracampo também parecem ser suturados, fazendo com que a sucessão dos turnos de fala se estabeleça de forma colada à imagem do sujeito enunciante (o sujeito se vê falando, diferente da experiência de diálogo fora do universo online). Ao inserir a fotografia e o stop motion na sessão, o analista opera um corte na própria dimensão do olhar do Outro.

A proposta de assistir junto com o analisante às animações, que reproduzem o próprio olhar daquele que compôs a cena, desconstrói em ato aquilo que o próprio setting propõe como meio. Logo, os olhares de analista e analisante se unificam e passam a fazer parte da cena, compondo uma nova perspectiva na qual o olhar é posto para fora de campo. Isso introduz uma suspensão que será preenchida no momento seguinte pelo retorno do olhar que aponta, por sua vez, à dimensão "off" do olho que tudo vê. Será através dessa suspensão, desse intervalo, que apostamos na possibilidade de experimentação de um novo sujeito não mais tão afetado pela dimensão obscena do olhar do Outro.

\section{Considerações finais}

O trabalho remoto com crianças é ainda um desafio, e não sabemos muito bem quais os limites e o alcance de nossas intervenções. Contudo, é diante dos impossíveis apresentados por situações como a que vivemos atualmente que podemos, de algum modo, reinventar nossa prática clínica.

Apesar do debate teórico sobre o atendimento psicanalítico online ainda apresentar algumas controvérsias, posicionamo-nos do lado daqueles que pensam que é possível sustentar um trabalho a partir dos termos oferecidos pelo cenário desse novo setting. É óbvio que são necessários alguns cuidados especiais, sobretudo no que diz respeito ao apetite do olho que, para a teoria lacaniana, aponta para o encanto suscitado pela fome de dar a ver produzido pelo enquadramento das telas.

O caso clínico apresentado nos permitiu pensar em modos de dar tratamento à questão do objeto olhar utilizando o dispositivo online, cuja natureza é propriamente escópica. Demonstramos como um certo domínio do olhar do Outro pode se dar através do discernimento entre o olhar de quem olha e a visão abrangente e integral que retorna das telas.

O manejo de imagens fotografadas, postas em movimento quadro a quadro (stop motion), viabilizou certa fragmentação da realidade, que produz para o paciente a opacidade do olhar do Outro - opacidade necessária para domá-lo ou dominá-lo. Aqui, remetemos ao ponto inapreensível da percepção, o ponto cego que, segundo Vivès (2012), torna-se a condição de toda percepção: "se fosse concedido ao sujeito perceber, captar totalmente o Outro, se o 
percebido fosse a contrapartida perfeita do real, o sujeito se confundiria com ele e reconheceria um estado de gozo absoluto" (Vivès, 2012, p. 6)

Se o fotografado motiva o trabalho imaginativo de recomposição de uma totalidade apenas sugerida (Frayze-Pereira, 2005, p. 100-101), o trabalho com a colocação das fotos em movimento inscreve na própria imagem novos sentidos que podem produzir separação entre o olho que vê e o olho que tudo vê. É manuseando esse "certificado de presença" (Barthes, 1984) que pretendemos transcender o olhar do Outro que nos constitui, ao mesmo tempo em que, através do ato fotográfico, produzimos um signo de seu desaparecimento.

Ressaltamos a própria resposta do paciente para tentar dominar o olhar do Outro: nos pareceu muito interessante a ideia de que, através do estabelecimento de um ensino, o garoto passe a se diferenciar daquele que é olhado, apresentando-se como aquele que é capaz de reproduzir a profundidade desse olhar. Vale ressaltar que não se tratava de qualquer ensino, mas sim aquele que viabiliza a instalação de um tipo de "curiosidade ensinante", que vetoriza o desejo de ensinar algo que se sabe e algo que não se sabe sobre o olho que o olha.

Ao final, constatamos que se o meio pelo qual o clínico atua é o "entre telas", um dos efeitos do trabalho será uma espécie de sutura daquilo que, em teoria cinematográfica, é chamado de campo e contracampo. Foi assim que a brincadeira com o stop motion pôde introduzir a possibilidade do analisante ver o seu olhar desde um lugar de fora do plano - algo que parece ter colocado em cena um tipo de suspensão que tem o potencial de fazer surgir um sujeito nessa lacuna, nesse espaço fora de campo que pode se ver não tão afetado pelo olhar obsceno do Outro.

\section{Referências}

Barthes, R. (2004). Sobre a fotografia. In R. Barthes, O grão da voz. (M. Laranjeira, trad.). São Paulo, SP: Martins Fontes.

Barthes, R. (1984). A câmara clara: notas sobre a fotografia (J. C. Guimarães, trad.). Rio de Janeiro, RJ: Nova Fronteira.

Belo, F. (2020). Clínica psicanalítica on-line: breves apontamentos sobre o atendimento virtual. São Paulo. Editora Zagodoni.

Bentham, J. (2008). O panóptico. T. Tadeu (Org. e trad.). Belo Horizonte, MG: Autêntica. (Trabalho original publicado em 1787).

Dunker, C. I. L. (2020). A arte da quarentena para principiantes [recurso eletrônico]. São Paulo, SP : Boitempo.

Ferenczi, S. (1992). A elasticidade da técnica psicanalítica. In S. Ferencz, Obras completas, v. IV. São Paulo, SP: Martins Fontes. (Trabalho original publicado em 1928).

Fink, B. (2017). Fundamentos da técnica psicanalítica: uma abordagem lacaniana para praticantes (C. Luchetta \& B. A. Berger, trads.). São Paulo, SP : Blucher; Karnac.

Frayze-Pereira, J. A. (2005) Arte, dor: inquietudes entre estética e psicanálise. Cotia, SP: Ateliê editorial. 
Jerusalinsky, J. (2017). As crianças entre os laços familiares e as janelas virtuais. In J. Jerusalinsky \& A. Baptista (Orgs.), Intoxicações eletrônicas: o sujeito na era das relações virtuais (pp. 39-55). Salvador, BA: Ágalma.

Lacan, J. (1965-1966). Le séminaire, livre 13: L'objet de la psychanalyse. Versão STAFERLA. Recuperado de http://staferla.free.fr/S13/S13\%20L'OBJET.pdf (Apresentação oral em 1965-1966, publicação inédita).

Lacan, J. (1985). O seminário, livro 11: os quatro conceitos fundamentais da psicanálise, 1964. Rio de Janeiro, RJ: Jorge Zahar Ed. (Apresentação oral em 1964, original publicado em 1973).

Lacan, J. (1985). O seminário, livro 20: Mais ainda, 1972-1973) (M. D. Magno, trad.). Rio de Janeiro: Jorge Zahar. (Apresentação oral em 1972-1973, original publicado em 1975).

Lacan, J. (1998). Observação sobre o relatório de Daniel Lagache: "Psicanálise e estrutura da personalidade". In J. Lacan, Escritos (pp. 653-691). Rio de Janeiro, RJ: Jorge Zahar. (Trabalho original publicado em 1960).

Lacan, J. (2003). Alocução sobre o ensino. In J. Lacan, Outros escritos (V. Ribeiro, trad., pp.302-310). Rio de Janeiro, RJ: Jorge Zahar.

Miller, J-A. (1966) "La Suture (Elements de la Logique du Signifiant)". Cahiers pour la analyse, $\mathrm{n}^{\mathrm{o}} 1$, janeiro/fevereiro.

Miller, J-A. (1999) Le divan. XX1 e siècle. Demain la mondialisation des divans? Vers le corps portable. Par Jacques-Alain Miller, par Eric Favereau, Paris: Liberation.

Miller, J-A. (2008). A máquina panóptica de Jeremy Bentham. In T. Tadeu (Org.), O panóptico (pp.89-126). Belo Horizonte, MG: Autêntica.

Oudart, J-P. (1969)"La Suture". Cahiers du cinéma, no 211 e 212, abril/maio 1969.

Ramos, F.P (2000). Teoria do cinema e psicanálise: Intersecções. In G. Bartucci (Org.). Psicanálise, cinema e estéticas de subjetivação (pp. 123-149). Rio de Janeiro, RJ: Imago.

Vivès, J.-M. (2012). Se um discurso pode ser sem fala/palavra, ele pode ser sem voz? In N. V. A. L Leite; J. G. Milán-Ramos \& M. R. S. Moraes (Orgs.), De um discurso sem palavras. (pp.43-49). Campinas, SP: Mercado de Letras.

Vivès, J.-M. (2018) Variações psicanalíticas sobre a voz e a pulsão invocante. (V. A. Ribeiro, trad.). Rio de Janeiro, RJ: Contra Capa.

Wajcman, G. (2006). La casa, lo intimo, lo secreto. In G. Wajcman, Las tres estéticas de Lacan. (pp. 93-115). Buenos Aires: Del Cifrado.

Winnicott, D.W. (1986). Varieties of psychotherapy. In C. Winnicott, R. Shepherd, \& M. Davis (Eds.), Home is where we start from; essays by a psychoanalyst. Harmondsworth: Penguin Books. (Trabalho original publicado em 1961).

Revisão gramatical: Transcrito Já LTDA

E-mail: contato@transcritoja.com

Recebido em novembro de 2020 - Aceito em outubro de 2021. 